\title{
High performance sport programs and emplaced performance capital in elite athletes from developing nations
}

\begin{abstract}
For elite athletes from developing countries, providing access to high performance services is often a low priority, when other issues such as basic social, health, and community needs take precedence. Little is known about how these athletes develop the skills necessary to compete at international events. Prior to the Commonwealth Games in Australia, a series of training camps were trialed, designed to expose athletes from a small group of developing countries in the Oceania region to the high-performance training environment. Drawing on data from focus groups conducted with athletes and coaches, the authors explore the struggles that occur as athletes negotiate the affects produced through the material and sensory world of their everyday lives. The authors propose the notion of emplaced performance capital to examine the complex interplay between field, capital and habitus and the place-events of training and performing. Implicit within these negotiations is how power is exercised in conflicts over resources to produce inequalities and marginalization. While the research is conducted in developing countries, the authors argue that athletes from developed countries are also situated in material and sensory environments producing affects that potentially impact performance.
\end{abstract}




\section{Introduction}

Elite athlete development in developing countries is often a low priority, when issues of poverty, hunger, and illiteracy are of greater concern (Andreff, 2006). The vast majority of sport development in developing nations is dependent on foreign aid, with corruption and exploitation emerging as additional issues for elite athletes (Andreff, 2006; Connor \& McEwen, 2011). Exploitation continues through "muscle drain" as athletes are "cherrypicked" for development in first world clubs or national teams (Connor \& McEwen, 2011, p. 811). Connor and McEwen (2011) argued that it is unclear how athletes from developing countries can be developed in situ. Nevertheless, athletes from these countries do compete on the international stage, and we argue that it is important to recognize how the environment within which athletes train and compete, impacts on performance opportunities. This may allow for an approach to the management of athletes, both in developing countries and in the broader world of elite athletes that considers how the competing body is an organism that changes in relation to the environment in which it is situated (Pink, 2011).

Research into effective athlete development has recognized that attention should be given to the context of development along with the complexity of the interactions between the athlete and the environments in which they are located (Hackfort, 2006; Wylleman \& Lavallee, 2004). Work has been conducted in this area from a sports psychology approach (Henriksen, Stambulova \& Roessler, 2010a; 2010b; 2011); however, this research does not extend to exploring how the body interacts with the material and sensory components of the environment. Researchers have also explored the psychosocial aspects of athlete development, such as the strains associated with various environments and the cognitive responses to those strains (Gledhill, Harwood, Forsdyke 2017; McKay, Niven, Lavallee \& White, 2008). Yet this work does not connect with how these strains might be experienced at 
an embodied level, nor does this approach consider how these strains might emanate from the material environment in which the athlete trains and performs.

Given that the moving body is the focus of athletic development, little sport management research has focused on this aspect beyond its composition, functionality, and performance measures. Kitchin and Howe, (2013) echoing earlier calls from Slack and Kikulis (1989) and more recently from Love and Andrew (2012) suggest that sport management might engage with social and critical theory from the discipline of sociology to extend its knowledge base. Sociologists Hockey and Collinson (2007, p. 116) suggest that there is a need to understand the "sensuous and sensing sporting body." However, sport management has not explored the embodiment of elite athletes or how it is situated within spatiotemporal settings. Kitchin and Howe (2013) suggested that bridging the disciplinary divide between sociology and sport management might occur through employing Bourdieu's (1990) practice theory to examine the micro-processes of embodiment, and the meso and macro-changes that impact at an individual level.

While Bourdieu's practice theory examines the body as it is situated within the social spaces in which it takes shape, this work does not extend to exploring how the sensing body moves through and is changed biologically as it interacts with the diverse components of the environment. We argue that it is timely to begin a dialogue that examines the changes that occur through embodied knowing and skills, but also how the sensing body is situated or emplaced within its material surroundings (Pink, 2011). This type of investigation takes sport management in a direction that considers how the athlete interacts and is affected by all components of their surroundings, and how the athlete's body is also transformed in the process. Accordingly, our purpose in this paper is to examine the material and sensory processes that produce affects and capacities which impact athletes' opportunities for development. Implicit in this task is understanding how conflict over resources, inequalities 
and marginalization, produce affects that impact in varying ways on the opportunities for developing emplaced performance capital. We examine athletes' emplaced performance capital through the interplay between field, capital, habitus, and the productive affects of the material and the sensory (we explain these concepts further in our theoretical approach) that comprise athlete's daily lives. We also consider how power is exercised to become a regular pattern, that can either reinforce inequalities or disrupt and break them down.

\section{Literature review}

From a sport development perspective, economic disparities between developed and developing nations produce resource constraints within the high-performance sport environments of developing nations and work to restrict athlete talent development. Collins and Buller (2003) refer to social exclusion in high-performance youth sport to describe how a lack of material and cultural goods (or performance resources), alongside the inability to participate effectively in economic, social, political, and cultural life leads to constraints on sporting success. While government and non-government agencies work to address gaps in resource provision and provide aid to talented athletes in developing nations (e.g., Olympic Solidarity), an individual's habitus acquired by experience and early socialization, as well as unequal access to economic, social, and cultural capital, continues to affect the potential for their development as an athlete. For instance, athletes from developing nations often exhibit material and social need but are not provided with sufficient support from their government agencies to enable them equal opportunities to perform at the highest level compared with athletes of developed nations. Some argue that developing nations of these kind can be described as small nations on the basis of, inter alia, population, GDP / economic prosperity and remoteness, and would not be able to operationalize their sport resources without external support (e.g., Commonwealth Games Federation or International Sport Federations), nor compete against the increasing investment in elite athlete development by major sport powers 
(Houlihan \& Zheng, 2015). As described by Sam and Jackson (2018), the economic scale of small states could be said to affect many facets of development of the sport sector particularly in the world of international sport. This is not surprising, given that much of the work in developing nations around sport is centered on sport-for-development or the use of sport to exert a positive influence on health, social, economic, community, and cultural outcomes (Schulenkorf, Sherry, \& Rowe, 2016) rather than the development of sport processes and systems that prioritize talent identification and development. We argue that both sport for development and sport development approaches do not consider the material and sensory, and the affects produced through the totality of the environment in which the athlete is situated. These interactions can produce a change of state that can either shut down capacities or open them up (Fox \& Alldred, 2017).

Henriksen, Stombulova, and Roessler (2010a; 2010b) overcame this lacuna somewhat through their organizational psychology and ecological perspective which offers a holistic approach to athlete talent development. A holistic approach extends the focus to a broader examination of factors that nurture an athlete's potential. Their ecological perspective melds two models: athletic talent development environment (ATDE) and environment success factors (ESF). They considered the athletic and non-athletic domains, as well as social setting, and the everyday environment of the athlete. The models also include the preconditions of success such as human elements (coaches and management resources), and financial and material elements (training and accommodation) (Henriksen, Stombulvoa, \& Roessler, 2010a). Previous research has highlighted the importance of the context in which athletic development takes place (Stambulova \& Alfermann, 2009; Stambulova, Alfermann, Statler, \& Côté, 2009), and Henriksen et al. (2010a; 2010b) build on this work. The addition of cultural artefacts, under the umbrella of organizational culture in the ESF model, is interesting as it includes several material elements such as clothing, buildings, and 
organizational charts. Other material elements, such as training facilities are also included as preconditions. A strong organizational culture, that focuses on a holistic approach, constitutes the norms that guide the socialization of new members. While these models are quite comprehensive and include many environmental elements, they focus on the behavioral changes that occur in relation to various environmental stimuli. Other sensory elements of the training environment, such as the aural and olfactory, are not considered. Models also tend to be static and do not account for the constantly moving environment, and how the body changes biologically as it interacts with the materiality of the environment in which it is situated. The sensuous and sensing sporting body, and how athletes "see, hear, feel, touch and smell" (Hockey \& Collinson, 2007, p. 118) within the sporting environment also escapes the attention of the two models.

How the sensing body is affected by the environment in which it is situated is touched on obliquely in the context of psychosocial strains, such as negative emotions or pressures that may impact on performance. These sources of strain occur in the competitive, organizational, and personal environment with consideration given to the cognitive responses of athletes (Fletcher, Hanton \& Mellalieu, 2006; Hanton, Fletcher \& Coughlan, 2005). McKay et al. (2008) extended on this work and explored the experiences of strain in elite track athletes in the United Kingdom. Their investigation highlighted findings from previous research identifying a range of organizational sources of strain including: training and personal issues (changes when training or competing and injury and illness), and lack of support from members of sports organizations (McKay et al., 2008). Competitive sources of strain included: feelings of fear, somatic concerns (inability to relax), concerns about preparation, and pressure to perform (McKay, et al., 2008). The only embodied elements considered within sources of competitive strain are centered within a cognitive framework and hence do not necessarily explore the more sensory aspects of various strains. There is 
also a certain degree of de-contextualization, as neither organizational nor competitive strains examine how the materiality of the environment may also create a range of strains. The importance of this omission is that sport organisations and management influence the environmental stimuli that surrounds an athlete (McKay et al., 2008). As Fox and Alldred (2017, p. 23) note, all kinds of matter "interacts and is affected by other materialities" including people and organisations, producing forces that work to affect potential capacities for action or conversely inaction. Fullagar (2017, p. 248) argues that this shift in thinking focuses on "what bodies can 'do' and how matter 'acts."” These forces can in turn work to affect the ebb and flow of the accumulation of various forms of emplaced performance capital.

In the next section we draw together Bourdieu's (1990) practice theory and Pink's (2011) emplacement to conceptualize our notion of emplaced performance capital.

\section{Theorising emplaced performance capital}

Shaw and Hoeber (2016) argued that the focus of sport management research should be not just be to identify gaps or spot filling, but rather should embrace alternative perspectives that might identify and fill gaps. They suggested that new theoretical concepts may advance and develop the field beyond current understandings. Foregrounding this suggestion, in this article, we draw on Bourdieu's (1990) concepts of habitus, field, and capital in conjunction with Pink's (2011) emplacement to conceptualize what we have called emplaced performance capital. Emplaced performance capital is comprised of the complex ecology of affective, material, and sensory aspects of place-events (Pink, 2011). Emplaced performance capital also examines the habitus, field, economic, cultural, social, and symbolic capital of elite athletes. Central to Bourdieu's practice theory, and most pertinent to this paper, is his notion of capital. Capital is a resource that individuals vie for in various fields. Each field, such as that of an elite sport, has its own operating logics which determine the 
most valuable types of capital to acquire (Bourdieu, 1990). Capital can be classified as financial resources, access to training and competition facilities, access to support networks including coaches, sport science specialists, and significant others. The acquisition of various forms of capital gives individuals positions of power within the field (Bourdieu, 1990). Together capital and field allow for an examination of how power can be exercised in ways that can reinforce inequalities. The exercise of power can also be employed to impose values and dispositions on others within the field.

To operate within the field, not only relies on the acquisition of capital, but also the specific embodied disposition (hexis) that together comprise the habitus of the field (Bourdieu, 1991). Habitus and hexis offer the opportunity to explore how embodied practices construct identity and difference within the context of a particular field. Habitus implies that one has acquired a degree of competence within the field, such as that of elite athletes. Bourdieu (1971, p. 182) refers to habitus as the "cultural unconscious" and it comes via "attitudes, aptitudes, knowledge, themes and problems, in short the whole system of categories of perception and thought" acquired through immersion within a particular field. Bourdieu (1990) likens this acquisition to a practical mastery, or feel for the game. The dispositions of habitus can be shaped and re-shaped in response to experience. How bodies act and appear within a field, reflect the embodiment of access to social, economic, symbolic, and cultural capital accumulated over time (Bourdieu, 1991).

Capital and its acquisition are therefore a pivotal aspect of how individuals construct their social space. Bourdieu (1986) proposed various forms of capital, and for the purposes of this paper, we draw on economic, cultural, social, and symbolic capital. Economic capital, one's access to financial resources, sits at the heart of all the other capitals. Bourdieu (1993) makes the point that those with more economic capital and little cultural capital will operate in a field differently to those who have more cultural capital and little economic capital. 
Economic capital can be converted into other forms of capital such as cultural capital, although it is not a simple or straightforward process.

Cultural capital refers to the knowledge, skills, and expertise that one accumulates, and is formed through the family, as well as other settings such as schools, work and the like. To take up or attain cultural capital is dependent on the individual's ability to receive and internalize the values and actions that stem from belonging to a particular group (Bourdieu, 1986). Cultural capital is also embodied, formed through ongoing labour and personal investment of time and practice (Bourdieu, 1986). It is also a resource, like other forms of capital, through which power is exercised, and a means through which some groups work to continue their dominance. Possession of cultural capital signifies that athletes have the dispositions to think, act in ways that improve their position within the field of elite athletes.

Social capital, like other forms of capital is formed in relation to cultural capital and refers to the "the sum of the resources, actual or virtual, that accrue to an individual or a group by virtue of possessing a durable network of more or less institutionalized relationships of mutual acquaintance and recognition" (Bourdieu, 1986, p. 251). Social capital is therefore dependent on other forms of capital an individual possesses. This form of capital can be increased through expanding one's network, but in order to achieve this, other forms of capital, such as economic, cultural or symbolic capital can influence the degree to which one can enhance their social capital. Symbolic capital is situated within the logics of social capital and refers to individual prestige and personal qualities (Bourdieu, 1986). Bourdieu (1980, p. 289) suggests that “to make one's name means making one's mark, achieving recognition (in both senses) of one's difference from others." Other forms of capital, such as economic, cultural, and social capital accumulate to bolster symbolic capital. Athletic success in terms of winning an event and making a name for oneself can also contribute to the accumulation of 
symbolic capital, with potential for additional benefits at a community-level derived from individual athletic performance.

However, while Bourdieu's (1986) practice theory is socially situated and temporally constituted over time, his work does not explore the material or affective aspects of a "feel for the game." Noble and Watkins (2003, p. 527) argued that "a 'feel for the game' is never just a feel for 'the game', but a feel for the ball, the pitch, the uniform, the other players, the coach, the referee, the spectators, the temporality of the game and not just its spatial qualities.” We extend this insight, through Pink's (2011) notion of emplacement, to explore elite athletes' material and sensing experience of their surroundings, and the implications for performance capital. Pink (2011) notes that to focus simply on embodiment overlooks how the competing body is located within a complex entanglement of processes. Emplacement recognizes that ways of knowing are more than just embodied but incorporate the material, affective, and sensory aspects of one's surroundings (Pink 2011). Ahmed (2004) contends that affects and emotions can be thought of interchangeably. What is important to consider is the actions they perform and what affects are produced, as Ahmed (2004, p. 4) argues the focus is on "[w] hat do emotions do"? Fox and Alldred (2017, p. 115) wrote that "emotions are part of a continuum of affectivity that links human bodies to the physical and social environment." The affects produced signify a change of state or of capacity in a being or entity (Massumi, 1988) that can be produce capacities or impede them. Similarly, the materiality of the environment, the entanglement of "geological forms, the weather, human socialities, material objects, buildings, animals and more" (Pink, 2011, p. 349) also produces affects and capacities. These affects, or forces, can acquire regular patterning if replicated through various events and across time and space (Fox \& Alldred, 2017).

As the athletic body moves through and interacts with the materiality and other components of the environment, it also does so as a sensing body, incorporating the senses, 
not just the five traditional senses of taste, touch, olfactory, aural and visual, but other senses such as heat and cold. Emplacement therefore recognizes the placed/spaced/temporal nature of experience. The body is situated as part of the environment and through feelings, sensations and interactions that occur in relation to that environment, the body is also physically transformed. In other words, the body " "becomes' in relation to other elements" of the place-event (Pink, 2011, p. 354). This is an important distinction, as it points to the biological changes that occur as athletes interact and are affected by the elements of environment in which they are situated in way that can produce or impede capacities for emplaced performance capital.

Drawing together emplacement and capital, allows an examination of the how various forms of capital are also emplaced, how they are shaped as the athlete feels or senses their way as part of their environment. We therefore argue that there are various forms of emplaced performance capital. Emplaced economic capital enables a becoming through the provision of material resources, such as high-performance training. Emplaced economic capital is also situated as a place-event through which relations of power work to enable or impede access to financial resources. For example, the access an athlete has to economic capital, and the impact this has on the sensing or feeling athletic body, can either open up or limit possibilities for development. This in turn can work to produce exclusion and marginalization. Emplaced cultural capital also becomes more than just embodied, it is linked to the sensing, feeling body as it is situated within the field of elite athletes. Emplaced cultural capital may be useful within the context of the competing home environment. However, the potential exists for an athlete to not be able to accumulate the cultural capital to compete in an international event. The reproduction of social capital is similarly dependent on ongoing work, situated within the place-event of the home environment. In a similar way to lack of economic capital, deficits of social capital may create the context for feelings of 
exclusion or marginalization. Lack of emplaced symbolic capital can also work to exclude athletes from accessing appropriate training facilities.

\section{Method and research context}

In 2016 an innovative programme, called Gather Adjust Prepare Sustain (GAPS), was developed to advance the support provided to athletes and coaches across the Oceania region in the lead-up to the Gold Coast 2018 Commonwealth Games. The project was jointly funded by the Commonwealth Games Federation, Menzies Health Institute Queensland, and City of Gold Coast, and gave athletes from Oceania Commonwealth nations and territories access to sports experts and facilities not readily available in their countries of origin. The GAPS program was open to all Oceania Commonwealth Games Associations (CGA), with at least one athlete from each of the 12 Oceania CGA's guaranteed a place. The program hosted 50 elite athletes competing in boxing, swimming, beach volleyball, lawn bowls, and athletics and 25 coaches, team management and venue managers from Vanuatu, Fiji, Tuvalu, Tonga, Solomon Islands, Cook Islands, Norfolk Island, Niue, Nauru, Kiribati, Samoa, and Papua New Guinea. Due to the diversity present in and between participating nations (see Sherry, Schulenkorf, Seal, Nicholson, \& Hoye, 2017) we intentionally employed nuanced and reflexive approaches in our work to account for linguistic and cultural differences between researcher and participant, as outlined below. The program was run over three camps spanning an 18-month period, with each camp running for five days starting December 2016 with consecutive camps held in July 2017 and January 2018. Participation in the GAPS programme produced success in terms of number of medals won.

\subsection{Sample and data collection}

The target group was identified as athletes, coaches and support staff of 12 nations of the Oceania region (and other Commonwealth nation participants) who were invited by the 
program host and funding partner to participate in the GAPS program. Athletes were nominated to participate in the program by each nation's leading sport organization (e.g., National Sport Organization or National Olympic Committee). Individual performance rankings or standings, or 'potential' to perform, were used as selection criteria.

Overall, 17 male and 13 female athletes (mean age 23.42 years, $S D=6.14$ years), and 6 male and 4 female coaches, and team managers participated in a focus group. In terms of sport, 2 female and 4 male athletes represented the sport of athletics across a range of disciplines (100m, 200m, 400m, 5000m, triple jump, javelin), 6 female and 2 male athletes represented beach volleyball, 1 male athlete represented boxing, 2 female athletes and 1 male athlete represented lawn bowls, and 5 female and 4 male athletes represented swimming across various disciplines (freestyle 50m, 100m, 200m 400m, 1500m; breaststroke 50m, 100m, 200m; butterfly 50m, 100m 200m; backstroke 50m; IM 200m).

Focus group interviews were conducted with athletes and coaches (of both genders). A focus group approach was utilized as it can provide access to groups, such as those of different ethnicities, that may be difficult to reach (Barbour, 2008). While individual interviews highlight the knowledgeable and meaningful perspectives of participants, offer opportunities for storytelling, and support the sharing of detailed experiences (Patton, 2002; Rothe, Ozegovic, \& Carroll, 2009), focus groups provide a flow of information based on the opinions and interactions within groups. Consistent with the oral traditions of various cultures, focus groups are similar to sharing circles in that they support the sharing of experiences or stories within a group setting and the capturing of common experiences across nations and ethnicities. Acknowledging the distinction between sharing circles and focus groups as a form of data generation (e.g., sharing circles hold sacred meaning to many cultures (Lavallée, 2009), we adopted a focus group approach that incorporated aspects of sharing circles to support the discussion of topics and issues in a supportive manner (Rothe et 
al., 2009). For example, extending discussion time until everyone was 'done sharing', rather than restricting the time allocated to the focus group. This approach enabled a culturally appropriate and sensitive method of developing a broad understanding of participants' oral descriptions of feelings, experiences, and modes of reasoning. Blending the focus group approach to incorporate aspects of sharing circle methods, allowed for a vibrant interview method.

Each focus group was specifically designed to manage the power relations between researchers and participants of different ethnicities, and the linguistic and cultural diversity of participants. For example, unease around English language skills created a clear power imbalance, as athletes may have been unfamiliar and uncomfortable with standard research protocols. To privilege the participant voice, it was also important to recognize varying degrees of written literacy and spoken English. In terms of language, English was not the first language for many participants, and it was necessary to ease discomfort among participants by developing supportive strategies to ensure that they fully understood the project, provide true informed consent, and participate in focus groups. We adopted strategies used by sportfor-development researchers in cross-national settings (e.g., Sherry et al., 2017) and provided information and obtained consent without assuming strong levels of literacy. The research team would sit with individual participants and speak with them about the project, and their rights as a participant. Often this occurred with the assistance of a coach or team manager to interpret when needed. This approach prioritized the protection of participants and provided equitable access to information. Similarly, focus groups were conducted in English. In cases where English was not the first language of participants, we used supportive strategies such as allowing more time for discussion and understanding of participants' own words and nuances. Coaches or team managers assisted with interpretation; however, English proficiency was sufficient, and continual cross-language translation was not required. 
To account for cultural diversity, 6 focus group leaders or facilitators ( 4 male and 2 female) residing in Australia comprised the interviewing team and represented diverse ethnic backgrounds (e.g., Fijian, Mauritian, Papua New Guinean) or had shared experience working with people of various ethnicities in academic or sport settings. Facilitators were experienced in conversational interview techniques and participated in a two-hour briefing meeting about the nature of the research, uniqueness of the participant group, and ethical standards including the practice of upholding reciprocity in the research process. For example, facilitators balanced the use of an interview schedule with conversational interview techniques to carefully manage the pattern of giving and taking between researcher and participant (Patton, 2002). Further, to build rapport with participants, facilitators were encouraged to engage informally with athletes and coaches in and around sport practice and before the scheduled focus group session. Familiarity among facilitators and participants allowed for a trusted and comfortable focus group setting, where people sat together in groups (e.g., a makeshift circle either on chairs or on the floor). Finally, a casual approach to the scheduled start and finish time of the focus group was used to account for cultural differences about the importance of time (Stewart \& Shamdasani, 2014). These approaches worked to encourage critical reflection through storytelling and were appropriate for the context (Kay, 2012).

Facilitators conducted a total of 10 focus groups in 2 sessions. Each session was designed to last around 30-45 minutes, as Packer-Muti, (2010) suggests long sessions can result in lethargy or apathy, yet based on the 'sharing circle' design adaptations explained earlier, focus groups ran up to 90 minutes. The first session explored the support and resources that have been provided or were available to athletes and coaches in their home nations. The session comprised 5 groups; 3 groups of athletes and 2 groups of a combination of coaches and support staff. Athletes were allocated a group based on their country of origin 
and sport. Similarly, coaches and support staff were allocated a group based on their country of origin and sport. The second session, which also comprised five groups was directed at gathering stakeholder reflections of the camp (e.g., expectations, benefits/values, areas for improvement), and how athletes and coaches may use experiences to build capacity. The criteria used to determine grouping in session one was also applied to session two. The data presented in this article draws on responses to questions posed in each focus group session.

\subsection{Data analysis}

Shaw and Hoeber (2016) argued that sport management research has become rather static in the qualitative methodologies employed. Advancing sport management research and tackling how we might answer research questions differently, requires an approach that challenges the "taken for granted assumptions" in sport management (Shaw \& Hoeber, 2016, p. 257). This opens up "possibilities of new and better approaches to inform our research" (Shaw \& Hoeber, 2016, p. 263). Our study has taken up this suggestion and used an approach to data analysis that is adapted from Jackson and Mazzei (2013). Jackson and Mazzei (2013, p. 261, italics in original) framed their process around the notion of "plugging in" theory with data, to use the theory to "think with the data". Hence our approach takes up a theoretical reading of the data that is both "within and against interpretivism" (Jackson \& Mazzei, 2013, p. 261, italics in original).

While Jackson and Mazzei (2013) argued that coding often obscures intricacies and tensions, the data was initially coded using NVivo, as it was used to inform a broader report to apprise stakeholders of how the program was received by those who participated. However, we also used the codes as a way into the data, providing us with assistance in identifying commonality of issues across the focus groups. In this way we were able to identify when athletes were discussing how the material and sensory produced affects that 
impacted on their capacities for developing emplaced performance capital. We then moved from the codes, back to the transcripts to see how comments were situated within the context of the discussion. We also began exploring how what we were reading might be connected to different theoretical approaches. Jackson and Mazzei (2013) argued that their process of thinking with theory draws on a range of theoretical frameworks, and this resonated with what we read as we engaged with the transcripts and various theoretical concepts. This prompted us to begin to think with data through Bourdieu's (1990) practice theory and Pink's (2011) notion of emplacement. Drawing these two approaches together we conceptualized the notion of emplaced performance capital as a way of thinking "something else" in and through the data (Jackson \& Mazzei, 2113, p. 262, italics in original).

Jackson and Mazzei (2013) also suggested that a series of analytic questions, informed by theoretical concepts, are put to work to think with and plug into the data. In this way, rather than searching for emerging themes or patterns, we took Jackson and Mazzei's (2013, p. 265) suggestion that key concepts from theory be used to plug "into the data and in turn, back into the theory”. Both Jackson and Mazzei (2013) and Pink (2011) were interested in the material, our interactions with other bodies, both human and non-human, as ways of thinking through social phenomenon. Thinking through a material lens, also enabled us to explore how participants interacted with the materiality of their environment, that is the matter, human and non-human, that works to produce affects and capacities (Fox \& Alldred, 2017). Our analytic questions were directed at understanding how various forms of emplaced performance capital worked to influence athlete's access to resources, and the potential consequences for performing. We also sought insights into how the sensory and material aspects of place-events converge in athletes' daily lives to produce affects, again with potential impact on performance. 
In the next section we undertake the task of plugging theory into the data to address our analytic research questions. This approach has produced mappings that helped to explore how the material and sensory produce affects and capacities which impact on athletes' development of emplaced performance capital. We open the discussion with an examination of emplaced cultural capital and habitus. Here we explore how the family, coaches and the church produce capacities that impact the everyday emplaced cultural capital and habitus of the athletes with varying affects. In deficits of emplaced performance capital, we examine the affects and capacities produced through deficiencies in the environment in which the athletes are situated. Finally displaced from the field allows us to consider athletes' struggles over access to the facilities through which to build their capacity for emplaced performance capital. We also examine how athletes experience the dislocating affects of performing at international events without emplaced performance capital.

\section{Findings and discussion}

\subsection{Emplaced cultural capital and habitus}

Emplaced performance capital was for some athletes constituted through the cultural capital of the family. For example, one athlete described their socialization into the sporting domain through their family: "My parents, they're into sports as well, so they pressure me and my siblings as well, they [teach] me, they played for [country name] as well." Other athletes also spoke of siblings who had represented their country who then helped shape emplaced cultural capital through helping the athlete to "push hard to get into the squad." As Pink (2011) suggests the embodied knowing and skills acquired in the movement through a place-event, in this case the family, physically transforms the body. The family was thus a space of becoming, the complex entanglement of learning how to be an athlete. The interactions with both their parents and their siblings, and the element of expectation also produced capacities for a disciplined and committed approach to building capacity for 
emplaced cultural capital. For example, a coach suggested that the family helped the athlete to remain committed and disciplined in their training and sport. The family and the home are important place-events, through which some athletes learnt how to embody becoming an athlete.

For other athletes, their coach assumed the same role as the family, with some describing them as akin to a father figure or a parent. Socialization, structuring, and becoming therefore occurred through athletes' encounters with the place-event of coaching. Coaches also recognized the importance of a familiar type of family habitus for not only connecting with the athlete, but also maintaining the athlete's interest: "Most of the athletes if we don't treat them like we treat our own kids, our own children, so they - they sort of lose their interest and their trust and they, it's sort of a burn out." Burn out as an affect reduces the athletes' capacities for taking up new forms of emplaced cultural capital. The deeply engrained nature of the family habitus can create tensions for athletes, as their dispositions are oriented towards maintaining and replicating the familiar habitus.

Athlete's encounters with their coaches were strongly shaped by their habitus, which emphasized a connection to family and the church. One coach discussed the durable interconnections of the family/church habitus:

So, every time they take the coach's assessments, most of the argument with discipline is that simple, it's the family discipline problem, which the church culture comes in and it comes out. It depicts the style and the lifestyle, the attitude of that family. So, I believe it starts from the families.

The church was a material and affective place-event that the athletes and their families moved through. The capacities produced through the disciplined practice of taking up and 
embodying the church lifestyle in turn worked to shaped athletes' capacities for developing emplaced habitus.

Another coach also explained how the church habitus informed the dispositions of the athletes: "Really and truly it moulds the athletes to that level where you want. Especially in terms of like work cultures and discipline. The church helps them.” As Bourdieu (2000, p. 177) argues "the habitus contributes to determining what transforms it." The church worked as a powerful place-event through which the athletes were transformed, both physically and in other ways that were quite difficult to capture, but nevertheless was a place of becoming a disciplined body. With the majority of athletes expressing deeply religious beliefs, the habitus they acquired through the church was an important disposition that they carried with them: "Yes. So, with the teachings of the bible and the church and teachings what we learn, you know discipline, attitudes, it is all there.” Bourdieu (1971, p. 194) suggests that in a particular habitus thought patterns "organize reality by directing and organizing thinking about reality." Athletes suggested that the church gave them certain dispositions that helped them adapt to changes in environment, such as when they travelled to compete:

Before we go on our trip and after we go on our trip we always have to go to church. Apparently for us it's good to ask for help, strength and all that to guide us throughout this, throughout when we're going on a trip for and then come back and thank him for whatever he's done.

This "strength", acquired through the act of prayer, was a deeply affective practice that for these athletes produced a range of capacities. A coach also suggested that this practice was reinforced through the material and affective connection to the athletes' bible: "They have their faith and they travel with their bible, that's church to them." The act of prayer was also a ritual and technique through which athletes attempted to manage the dislocating experience of travel and movement into another place-event. While habitus can be modified and adapted 
to take up and embody new experiences, at times the weight of early experiences can work to constrain its adaptability (Bourdieu, 1990).

\subsection{Deficits of emplaced performance capital}

Coaches suggested that economic capital provided access to knowledge, such as nutrition, strength, and conditioning. These high-performance services offered the opportunity for athletes to be transformed through the capacities of embodied knowing and skills, as well as through the interactions with high-performance support professionals. In this way the biological body is changed as it interacts with the various components (Pink 2011) that comprise the high-performance environment. However, in the Oceania Nations, the lack of emplaced economic capital meant that the task of providing high-performance support often fell to the coaches, the athlete themselves or the limited volunteer staff: "so coaches have to do everything, diet, strength and conditioning." Shaw and Pooley (1976), more than 40 years ago, identified that economic factors play an important role in the success of athletes from developing nations. We would argue that this situation persists.

In an effort to overcome some of these deficiencies one athlete, sensing that diet was an important aspect that affected their performance, sought to build their capacity for producing cultural capital through researching nutrition online. In some ways this athlete acquired a degree of expertise that contributed to their overall emplaced performance capital.

When we prepared for the Pacific Games ... I didn't watch my diet, but for Olympics I tuned in on diet big time. I could see - a big difference - in that training camp. Just with the diet change. Just simple diet change ... like I really had to research because I'm not really - I don't know that. So I had to research online what I could find and it takes a lot of time. Research the right diet ... and what should we be doing. Whereas like a - if there were helpful people around, we don't have to waste all that time. It's, oh go to this guy, you know. He says, okay, what's the best training for this. When do we slow down training, you know, just stuff like strength and conditioning. It's a learning process but that could be cut in half if we had people that knew about it already there. 
The athlete's pedagogical relation to self, learning how to change their body through diet gave them the capacity to produce the cultural capital necessary to physically transform their body. While the athlete speaks of a "simple diet change", the excerpt reveals the affects working to produce sense of frustration with the emotional investment of time, the uncertainty, and then feeling the different embodiment and capacities produced through the change in diet. While it is difficult to know the degree of knowledge acquired through this research, we suggest that the athlete's capacity for producing emplaced performance capital was not the same as those who had access to high-performance dietary experts. These experts not only provide direct and personalized information and knowledge, but the relational interaction also produces affects that offer the potential for a more focused change in state and the development of new capacities.

For other athletes accessing regular nutrition was often a struggle. Coaches suggested that they often hosted a lunch or dinner after training which was "sitting down time and sharing food post training is the cultural thing that we like to do ... so at least we know we are supporting the athlete and putting food in their belly." Another coach suggested that athletes struggled on a daily basis to meet their nutritional needs. The food they consumed was the material and non-human element through which the body was potentially transformed opening up opportunities for the production of new capacities. However, such transformation, or the capacity to build the emplaced performance capital necessary to compete on the international stage, is denied simply by virtue of being unable to afford or access regular nutrition to sustain a high-performance athlete. The affects produced through such deficiencies potentially reduce the athletes' capacities for performing both in training and while competing.

Often athlete's capacity to transform their bodies through training, and hence their emplaced cultural capital, was linked to the family's economic capital. Collins and Buller 
(2003) also highlighted that social background and financial support were development constraints that athletes in first world countries had to negotiate, but not the affects produced through such deficiencies. Within the present study, a coach discussed how deficiencies of emplaced economic and cultural capital were intertwined to produce affects.

The families, they're not really well off ... you're paying a track fee every day some of these families can't meet those - that's why we lose a lot of people from sports. So financially, if a family's struggling financially, that kid ... will have problems. Coming to daily training and getting all the things they need. That's one problem that they suffer.

Another coach suggested that the affects produced through the lack of economic capital, the embarrassment, feelings of deficiency, loss of face in the community, through the family's inability to provide economic capital hindered the capacities of athletes to produce emplaced cultural capital through access to training. The intensity of these place-events held the potential to force the athlete away from the sport, and if they chose to stay, left them exposed to daily feelings of deprivation. The relations of power exercised through deficits of economic capital worked to create feelings of exclusions and even marginalization. Money, and its lack, was a material object around which circulated a range of emotions, that in turn produced a range of affects. As we have argued, affects represent a change in the capacities or state of athletes, and the constancy of the daily negotiations with deficits of economic capital worked as another hinderance to the development of emplaced performance capital.

\subsection{Dis-placed from the field}

Within the field of elite sport in the athletes' country of origin, access to resources was heavily contested and the resultant struggles for access produced a range of affects and changes in capacities. Bourdieu (1990, p. 72) argues that for a field to function "there have to be stakes and people prepared to play the game, endowed with the habitus that implies 
knowledge and recognition of the immanent laws of the field ... and so on." While athletes may have been prepared to "play the game" a lack of emplaced capital, in all forms, left them experiencing a sense of frustration that they were often unable to access facilities to train. For example, the lack of symbolic capital for athletes in one Oceania nation resulted in another elite sport with high volumes of capital, exercising power to ensure that they had primary access to training facilities. This meant that athletes did not have access to regular or ongoing training facilities: "So most of the time we're trying to tailor our workouts around the availability of the stadium or the tracks. So, every Friday we go and check whether it's open next week." The athletes and their coaches had attempted to negotiate with those who ran the facilities, but without the power resources of accumulated capital their efforts appeared futile:

Well we sat down with the people who run the facilities and we've asked them, okay, what are the bookings that [country name and elite sport] has and what are the available times? Maybe we could communicate that with all the other clubs and the athletes through Facebook because everyone's on Facebook and tell them that this time it's closed, this time it's open. So that they can tailor their workouts accordingly.

This exchange suggests that coaches and athletes also draw into their negotiations emplaced social capital to facilitate the access into training facilities. Athletes also suggested that having the right connections or social capital expedited access to the training facilities: "One of our sprint coaches ... the woman that runs the facility, she included her daughter on the track team." Other athletes suggested that they too had to employ forms of social capital to bribe security guards to access facilities that may have been off limits to them: "This is your betel nut (an addictive drug chewed as a mouth freshener) and then you go in training, yeah. Here my friend. There's food, food for you." The relations of power associated with the place-event of training worked to produce a sense of exclusion for many of the athletes, and 
redirected energies and time toward the constant use of negotiation tactics and attempts to control uncertainty and unpredictability in the day-to-day environment.

The majority of athletes indicated that the struggle over resources meant that they often had to train on surfaces or in facilities that were materially and sensorially very different from those they will encounter when they compete on an international stage. For example, some beach volleyball athletes trained on concrete or bitumen surfaces, which meant that they were unlikely to ever practice diving for a ball. Other athletes suggested that they would have to train on surfaces that were "muddy" or "not levelled" or were on a "beach at low tide." Athletes also had little opportunity to train on synthetic surfaces. Contact with the different surfaces, were place-events with specific figurations and affects that were entirely different from those they would encounter when they compete at international events. One athlete suggested that this situation was "Very challenging for us but we're trying to make use of what we have and all that." Rather than training producing capacities for enhancing emplaced performance capital, the affects produced held the potential to produce unwanted capacities as athletes expended precious energy negotiating the different sensory and material environments. Collins and Buller (2003) also argue that lack of access to appropriate facilities was an impediment to development of the youth athletes in their study. Access to physical infrastructure has also been identified as a significant factor successful elite sports policy (Ibsen, Hansen, \& Storm, 2011; Stewart, 2011). However, as we have argued throughout this paper, highlighting deficits in resources is just the beginning, attention also needs to be given to the affects produced through such deficiencies. These deficits can become imprinted on the body, transforming it in undesirable ways. Sports managers and organizations are responsible for producing the physical spaces, or place-events of training and performing, they therefore need to become attuned to unwanted patterns or forces that may replicate deficits and reproduce feelings of marginalization and exclusion. 
A deficiency of emplaced economic capital also meant that athletes from outside main regional centres, or capital cities (who considered themselves "lucky" to have highperformance training facilities) in the 12 nations examined, had to travel to gain access to facilities. Coaches mentioned athletes who had to walk or run distances before they could actually begin training: "Some guys may find it hard to get to the venues ... We have an athlete, a kid that runs thirteen kilometres to get to training ... The worst case we've got is a boy that walks six hours ... so, it's having those everyday opportunities." Issues of security arose in relation to having to run outside the safety of training facilities, particularly for women. We suggest that as the performing body knows and learns through movement (Pink, 2011), so too does it come to know in relation to the affects and emotions produced through the environment in which it is situated. We argue that these athletes are learning that they are less, because they have very different experiences of accessing training. In their becoming as an athlete, they face constant challenges linked to the physical environment in which they are situated that impedes their capacities to train their bodies in the same way as others who have ready access to facilities.

A similar form of struggle over resources occurred in relation to the various sports federations in the Oceania nations. Some athletes suggested that they felt that they lacked the social and symbolic capital to position themselves on the "good side" of the federations. Failure to be able to do so often produced affects that left athletes feeling as if they were being further excluded, with several athletes suggesting that "they tend to forget about us." This bias also extended to preferential treatment for athletes in their favoured club. Delay tactics and failure to pass on funding (or other support), were also implied as elements of bias. There was a suggestion that support was only forthcoming if the athlete was successful and built their symbolic capital through doing "something good" in terms of their performance. An athlete commented on this lack of support "When you're injured, they don't 
want to know you." As Evans and Davies (2012, p. 624) argued "policy discourses ... are always and inevitably mediated for individuals through their material (flesh and blood, sentient, thinking and feeling) bodies." As sentient, thinking and feeling bodies, athletes felt a sense of anger, frustration and marginalization, particularly for those who were not in major cities. The unwanted transformation of the athlete's body, in the form of injury, and the lack of forthcoming help related to their provincial location, left athletes emplaced in a field with very little capital. However, one athlete suggested they had attempted to employ various forms of emplaced capital to access help: "It's like not particularly organized, like you have to go your own way and like search for it. Like the federation just sits there and expects you to heal." This entanglement of largely negative experiences left athletes with feelings of displacement and despair. Following Massumi's (1988) line of thinking, the affects produced can signify a change in the state or capacity of the athlete. This prompts us to pose the question of what unwanted biological changes in capacity are produced through such conditions of constant deprivation?

For other athletes, a sense of displacement also occurred when travelling and performing at international events. Athletes felt a sense of fear, and in this instance, we suggest lacked the emplaced performance capital that would enable them to feel comfortable performing in the field of an international place-event. Several female volleyballers spoke of the affects produced through the requirement that they wear a bikini to compete in the field of beach volleyball. One athlete discussed the dislocating experience of encountering the different physical and social performance environment: "yeah, this is because in our country we have different cultures. So we are not allowed to wear bikinis and stuff." It was the athletes' emplaced habitus and cultural capital, formed through the church environment, that created a moral imbroglio, making it difficult for them to adapt to the new context. Making sense of these complex entanglements, the discomfort at being in a different space, wearing a 
garment that provoked feelings of unease, was a powerful embodied experience that this group of female athletes had to negotiate.

Another athlete described the intense sensory experience of the first time they competed at an international event: "First time performing in front of a huge crowd in China ... it was pretty heavy ... Your whole body goes ... It's a different feeling altogether ... It's different from being at home, training." The environment into which the athletes moved, may in some ways be materially similar, for example a stadium, however, the convergence of things in process, the emotions the athletes experienced, the sensation of feeling a heavy body, the sheer numbers of other people crowding the place-event, the weight of performance expectations, the sense of everything being different left the athlete feeling disconnected from their body and rendered the place as deeply unsettling. While athletes may have been familiar with the field of elite athletes within their home environment, when they encountered the international field, rather than feeling like a "fish in water" (Bourdieu \& Wacquant, 1992, p. 127) they experienced unfamiliarity and discomfort. This does not mean that athletes are unable to adapt and transform. Disjunctures, such as exposure to new fields with new dispositions may drive a restructuring of the habitus. In this transformation, consideration also needs to be given to how learning occurs in movement as the athlete feels or senses their way through the place-event, and "becomes" in relation to the unfamiliar elements of the stadium. We now consider the practice implications that arise from our analysis.

\subsection{Practice implications}

Our emplaced performance capital approach allows sport management to develop a more nuanced understanding of how athletes engage with and are affected by their surroundings. Gaining an insight into the environment that forms and continue to form athletes from developing countries might assist organizations in first world countries to 
interact with these athletes in a more culturally sensitive manner. Understanding the cultural context, including the family habitus, and its importance in producing the capacities for emplaced cultural capital is central to this task. At a more targeted level, sports managers can develop their awareness of an athlete's background, which can work to produce capacities (particularly spiritual background, as is the case in this article), but can also be a place of deficit, which may reduce the production of capacities. This type of patterning can work to reproduce athlete's experiences of marginalization.

Our material and sensory approach also highlights how disadvantage and marginalization is often more than economic and can be produced through the material and sensory environment in which athletes train and perform. All athletes experience the material and sensory world in ways that produce different capacities, including how power is experienced, producing enabling or constraining affects. As we have suggested the power relations at work are often perpetuated through regular patterning over time, reinforcing marginalization. It is then incumbent on sport organizations and managers to attempt to disrupt this form of patterning through practices that create connections to a more equitable environment. This may involve confronting injustices to promote changes that challenge assumptions that the material and sensory are unimportant aspects of developing emplaced performance capital. While this may be difficult in a developed country and even more so in a developing country, recognizing how power can be exercised to exclude athletes, through restrictions in accessing material resources, can work to disrupt the forces and affects that constrain the development of emplaced performance capital. As Washington and Patterson (2011) note this allows for an alteration in the relational dynamics in the field through shifting the logics, norms and values in ways that do not exclude those with the least power. On this point and to inform practice, we draw from the work of Sherry et al. (2017) to advocate for the adoption of more participatory and collaborative approaches in the 
development and design of sport programs that focus on the contributions of local voices in local cultures, and work to integrate a range of insights to better understand the complexity of interactions between athletes and his or her environment. A significant aspect of participatory and collaborative approaches is including participants as equal partners in the development of programs (Spaaij. Schulenkorf, Jeanes \& Oxford, 2018). For example, in practice settings, while mapping biological or physical changes of the performing body is important, coaches and sport managers must also recognise how athletes balance and negotiate the affects or capacities produced through different training and competition environments that also work to physically transform the body. Sports managers from developing and host nations who are at the forefront of training camps, could work together to intentionally design and structure camps that establish an environment conducive to adaptation, engagement, and inclusion in both sport and non-sport activities.

Providing a sporting environment that considers the material and sensory, is important as these factors can hinder or enhance the development of capacities for producing emplaced performance capital. Sports managers and organizations need to be attuned to how the material and sensory produce affects. For example, managers could 'set the scene' for athletes prior to events or training camps through ongoing interactions, such as sharing information on the expectations and the environment of the host site, so that athletes can gradually become familiarised with new settings. Allowing for a familiarization period, as athletes settle into the unfamiliar environment and introducing sensory elements that reflect productive affects from the home environment, may also assist athletes to attune to different settings. As we have argued deficits become imprinted on the body, particularly when that body is continually exposed to an environment of deficiency. This requires an approach that allows for management as a "messy, ambiguous, political and fragmented" activity. (Frisby, 2005, p. 5). This contrasts with mainstream organizational approaches which rely on 
rationalities that often do not allow for alternative or diverse points of view. Accounting for the material world of athletes, in all its forms, may in part be reliant on funding. However, to foster a high-performance environment focused on success, and develop emplaced performance capital requires attending to how changes of capacities can be produced or hindered by the types of training environments that organizations provide for athletes. In this way athletes can become attuned to an environment that is more reflective of that which they may encounter when performing.

\subsection{Concluding comments}

In this article we have sought to gain an insight into how the material and sensory produce affects that impact the capacities for producing emplaced performance capital in athletes from developing nations. The family and the church were important and familiar place-events through which athletes constituted emplaced cultural capital. Cultural context was important in understanding how the athlete was emplaced within a particular cultural system. While familiarity with the sensory, affective and material context of home was reassuring, when athletes travelled their emplaced performance capital collided with another world that was sensorially and materially different. When confronted with this environment, athletes felt a range of disquieting emotions that threatened their performance. As Pink (2011, p. 347) writes the "body is an organism that changes biologically in relation to the diverse components of its environment." The biological change that occurred when athletes came into contact with the different environment created an affective change that was unsettling and had potential to constrain their capacity to develop a "feel for the game."

Lack of other forms of emplaced performance capital, such as economic capital, seriously impeded athletes' access to high performance services which left them with little option but to rely on their families or coaches for material support. The athletes had little 
access to knowledge, such as nutrition, strength, and conditioning as well as recovery practices that could enhance both their training and performing. Athletes were emplaced in a field where they lacked resources to become and perform at an elite level. Lack of emplaced economic capital was a constant that characterized the daily lives of these athletes and generated a range of affects that worked to exclude and marginalize them. The affects produced intense feelings of uncertainty, frustration, and worry, that not only forced some athletes away from their sport, but also impacted on the degree to which they could develop as elite athletes. We would argue that it is not only athletes from developing countries that struggle with the affects produced through changes in the material and sensory world they inhabit.

Access to other resources such as adequate and safe training facilities created a sense of displacement for many athletes. Unsuitable surfaces meant that athletes experienced the spaces they trained in as material and sensory spaces of deficit. Weekly or daily negotiations for access to facilities, often to little avail, worked to affect athlete's everyday experiences of training. Expressions of frustration, disconnection, and some cases fear both at home and abroad, displaced athletes from the field of elite athletes. This displacement was further intensified for athletes when they were injured, and policies of sports federations did not support them. Athletes suggested that the sports federations would only support them when they were achieving, a difficult proposition given the deficits of emplaced performance capital, impossible when injured. The lack of support was a place-event that worked to produce an unwanted becoming, an injured athlete. The power relations exercised left athletes displaced in a field where they felt they had little emplaced performance capital.

Programs such as GAPS offer athletes from developing countries an opportunity to experience what it is like train in and be exposed to a high-performance environment, so that when confronted with the different material and sensorial environment it is less daunting. 
With the growth of sports labour migration from the Global South to the Global North (Stewart-Withers, Sewabu, \& Richardson, 2017) we argue there is a need to understand the cultural, material, and sensory world of these athletes. While this research has examined the experiences of athletes from developing nations, we suggest that athletes from developed countries are also affected by the material and sensory world of training and performing in ways that enhance or negate the production and accumulation of emplaced performance capital. 


\section{References}

Ahmed, S. (2004). The cultural politics of emotion. Edinburgh: Edinburgh University Press.

Andreff, W. (2006). Sport in developing countries. In W. Andreff \& S. Szymanksi (Eds.), Handbook of the economics of sport (pp. 308-315). Cheltenham: Edward Elgar.

Barbour, R. (2008). Doing focus groups. London: Sage.

Bourdieu, P. (1971). Intellectual field and creative project. In M.F.D. Young (Ed.), Knowledge and control: New directions in the sociology of education (pp. 161-188). London: Collier-Macmillan.

Bourdieu, P. (1980). The production of belief: contribution to an economy of symbolic goods. Media, Culture \& Society, 2, 261-293.

Bourdieu, P. (1986). The forms of capital. In J.G. Richardson (Ed.), Handbook of theory and research for the sociology of education (pp. 241-258). New York: Greenwood Press.

Bourdieu, P. 1990. The logic of practice. Stanford: Stanford California Press

Bourdieu, P. (1991). Language and symbolic power. Trans. G. Raymond \& M. Adamson. Cambridge: Polity Press.

Bourdieu, P. (1993) Sociology in question. London: Sage.

Bourdieu, P. (2000). Pascalian meditations. Oxford: Polity Press.

Bourdieu, P. \& Wacquant, L. (1992). An invitation to reflexive sociology. Chicago: University of Chicago Press. 
Collins, M. F., \& Buller, J. R. (2003). Social exclusion from high-performance sport: Are all talented young sports people being given an equal opportunity of reaching the Olympic podium? Journal of Sport and Social Issues, 27(4), 420-442.

Connor, J., \& McEwen, M. (2011). International development or white man's burden? The IAAF's regional development centres and regional sporting assistance. Sport in Society, 14 (6), 805-817.

Evans, J., \& Davies, B. (2012). Embodying policy concepts. Discourse: Studies in the cultural politics of education, 33, 5, 617-633.

Fletcher, D., Hanton, S., \& Mellalieu, S.D. (2006). An organizational stress review: Conceptual and theoretical issues in competitive sport. In S. Hanton \& S.D. Mellalieu (Eds.), Literature Reviews in Sport Psychology (pp. 321-374). New York: Nova Science.

Fox, N., \& Alldred, P. (2017). Sociology and the new materialism. London: Sage.

Frisby, W (2005). The good, the bad, and the ugly: Critical sport management research. Dr Earle F. Zeigler Lecture. Journal of Sport Management, 19, 1-12.

Fullagar, S. (2017). Post-qualitative inquiry and the new materialist turn: implications for sport, health and physical culture research. Qualitative Research in Sport, Exercise and Health, 9, 2, 247-257.

Gledhill, A., Harwood, C., \& Forsdyke, D. (2017). Psychosocial factors associated with talent development in football: A systematic review. Psychology of Sport and Exercise, 31, 93-112. 
Hackfort, D. (2006). A conceptual framework and fundamental issues investigating the development of peak performance in sports. In D. Hackfort, \& G. Tenenbaum (Eds.), Essential processes for attaining peak performance (pp. 10-25). Oxford: Meyer \& Meyer.

Hanton, S., Fletcher, D., \& Coughlan, G. (2005). Stress in elite sport performers: A comparative study of competitive and organizational stressors. Journal of Sports Sciences, 23, 1129-1141.

Henriksen, K. Stambulova, N., \& Roessler, K. (2010a). Holistic approach to athletic talent development environments: A successful sailing milieu. Psychology of Sport and Exercise, 11, 212-222.

Henriksen, K. Stambulova, N., \& Roessler, K. (2010b). Successful talent in track and field: Considering the role of the environment. Scandinavian Journal of Medicine and Science in Sport, 20 (Suppl. 2), 122-132.

Henriksen, K. Stambulova, N., \& Roessler, K. (2011). Riding the wave of an expert: A successful talent development environment in kayaking. The Sport Psychologist, 25, $341-362$

Hockey, J., \& Allen Collinson, J. (2007). Grasping the phenomenology of sporting bodies. International Review for the Sociology of Sport, 42(2), 115-131.

Houlihan, B., \& Zheng, J. (2015). Small states: sport and politics at the margin. International Journal of Sport Policy and Politics, 7(3), 329-344.

Ibsen, B., Hansen, J., \& Storm, R. (2011). Elite sport development in Denmark. In B. Houlihan \& M. Green (Eds.), Routledge handbook of sports development (pp. 386398). Milton Park: Routledge. 
Jackson, A. Y., \& Mazzei, L. A. (2013). Plugging one text into another: Thinking with theory in qualitative research. Qualitative Inquiry, 19 (4), 261-271.

Kay, T. (2012). Accounting for legacy: Monitoring and evaluation in sport in development relationships. Sport in Society, 15(6), 888-904.

Kitchin, P. J. \& Howe, D. (2013). How can the social theory of Pierre Bourdieu assist sport management research? Sport Management Review, 16, 123-124.

Lavallée, L. F. (2009). Practical application of an Indigenous research framework and two qualitative Indigenous research methods: Sharing circles and Anishnaabe symbolbased reflection. International Journal of Qualitative Methods, 8(1), 21-40.

Love, A., \& Andrew, D. P. S. (2012). The intersection of sport management and sociology of sport research: A social network perspective. Sport Management Review, 15, 244-256.

McKay, J., Niven, A., Lavallee, D., \& White, A. (2008). Sources of strain among elite UK track athletes. The Sport Psychologist, 22, 143-163.

Massumi, B. (1988). Translator's foreword. In G. Deleuze \& F. Guattari, A thousand plateaus (pp. ix-xix). London: Athlone.

Noble, G., \& Watkins, M. (2003). So how did Bourdieu learn to play tennis? Habitus, consciousness and habituation. Cultural Studies, 17(3-4), 520-539.

Packer-Muti, B. (2010). Conducting a focus group. The Qualitative Report, 15(4), 10231026.

Patton, M. Q. (2002). Qualitative research and evaluation methods (3rd ed.). Thousand Oaks, CA: Sage. 
Pink, S. (2011). From embodiment to emplacement: Re-thinking competing bodies, senses and spatialities. Sport, Education and Society, 16(3), 343-355.

Rothe, J. P., Ozegovic, D., \& Carroll, L. J. (2009). Innovation in qualitative interviews: 'Sharing Circles' in a First Nations community. Injury Prevention, 15(5), 334-340.

Sam, M., \& Jackson, S. J. (Eds.). (2018). Sport policy in small states. Routledge.

Schulenkorf, N., Sherry, E., \& Rowe, K. (2016). Sport for development: An integrated literature review. Journal of Sport Management, 30(1), 22-39.

Shaw, S., \& Hoeber, L. (2016). Unclipping our wings: Ways forward in qualitative research in sport management. Sport Management Review, 19, 255-265.

Shaw, S., \& Pooley, J. (1976). National success at the Olympics: An explanation. In C. Lessard, J. P. Massicotte, \& E. Leduc (Eds.), Proceedings of the 6th international seminar: History of physical education and sport (pp. 1-27). Trois Rivieres, Quebec.

Sherry, E., Schulenkorf, N., Seal, E., Nicholson, M., \& Hoye, R. (2017). Sport-fordevelopment: Inclusive, reflexive, and meaningful research in low-and middle-income settings. Sport Management Review, 20(1), 69-80.

Slack, T., \& Kikulis, L. M. (1989). The sociological study of sport organizations: Some observations on the situation in Canada. International Review for the Sociology of Sport, 24, 179-199.

Stambulova, N., \& Alfermann, D. (2009). Putting culture into context: Cultural and crosscultural perspectives in career development and transition research and practice. International Journal of Sport and Exercise Psychology, 7(3), 292-308 
Stambulova, N., Alfermann, D., Statler, T., \& Côté, J. (2009). Career development and transitions of athletes: The ISSP position stand. International Journal of Sport \& Exercise Psychology, 7, 395-412.

Stewart, B. (2011). Sports development and elite athletes: The Australian experience. In B. Houlihan \& M. Green (Eds.), Routledge handbook of sports development (pp. 418432). Milton Park: Routledge.

Stewart, D. W., \& Shamdasani, P. N. (2014). Focus groups: Theory and practice (3rd Edn.). Los Angeles: Sage.

Stewart-Withers, R., Sewabu, K., \& Richardson, S. (2017). Talanoa: A contemporary methodology for sport management. Sport Management Review, 20, 55-68.

Washington, M., \& Patterson, K. (2011). Hostile takeover or joint venture: Connections between institutional theory and sport management research. Sport Management Review, 14, 1-12.

Wylleman, P., \& Lavallee, D. (2004). A developmental perspective on transitions faced by athletes. In M. R. Weiss (Ed.), Developmental sport and exercise psychology: A lifespan perspective (pp. 503-523). Morganton: Fitness Information Technology. 